\title{
Evaluation of Reactivity Profile of Non-Structural Protein C of Peste-Des-Petits-Ruminnats Virus
}

\author{
Bhadouriya Sakshi ${ }^{1}$, Dheeraj Choudhary ${ }^{1}$, Ajay Yadav ${ }^{1}$, \\ S. Chandra Sekar ${ }^{1}$, V.V. Dhanesh ${ }^{1}$, M. Sankar', Kaushal K. Rajak ${ }^{2}$, \\ R.P. Singh ${ }^{2}$, M.A. Ramakrishnan ${ }^{1}$ and Dhanavelu Muthuchelvan ${ }^{1 *}$ \\ ${ }^{1}$ Division of Virology, ICAR-Indian Veterinary Research Institute, Mukteswar, Nainital \\ District, Uttarakhand 263 138, India \\ ${ }^{2}$ ICAR-Indian Veterinary Research Institute, Mukteswar, Nainital District, \\ Uttarakhand 263 138, India \\ *Corresponding author
}

\section{A B S T R A C T}

\section{Keywords}

Peste-des-petitsruminants, PPR, Nonstructural protein $\mathrm{C}$, PPRV, Antibody kinetics

Article Info

Accepted:

26 January 2018

Available Online:

10 February 2018
Peste-des-petits ruminants (PPR) is an economically devastating viral disease of sheep and goats. In the present study, we have evaluated the reactivity profile of the recombinant non-structural protein $C$ of PPR virus with vaccinated and convalescent goat sera in an indirect ELISA. The antibody against this protein is getting produced in both vaccinated as well as in convalescent animals. Further, we evaluated the antibody production kinetics in vaccinated goats and found that antibodies against this protein is getting produced from the $14^{\text {th }}$ day of post-vaccination and persists till the $40^{\text {th }}$ day of the study period. The data generated in this study will be useful for the development of DIVA vaccine and diagnostics against PPR.

\section{Introduction}

Peste-des-petits ruminants (PPR) is a viral disease of small ruminants caused by PPR virus. The international agencies FAO and OIE target the progressive control and eradication of this disease by 2030 (Parida et al., 2015). The disease can occur in many forms like peracute, acute, and in-apparent forms and the morbidity and mortality and case fatality rates vary accordingly. Generally, the clinical symptoms are more severe in goats than in sheep (Sen et al., 2010). The etiological agent, PPR virus belongs to the genus Morbillivirus of the family Paramyxoviridae. The genus Morbillivirus harbors many important pathogens like rinderpest in cattle, measles in humans, Canine distemper in Canines and morbilliviruses of marine animals. In the similar line of global rinderpest eradication, now FAO and OIE target the global eradication of PPR by 2030. Similar to rinderpest, this virus also occurs as single 
serotype and genetically it can be classified into four distinct lineages (I, II, III, and IV) based on F gene (Shaila et al., 1996) and $\mathrm{N}$ gene (Kwiatek et al., 2007). Occurrences of all four lineages have been reported in many countries of Africa whereas only lineage IV has been reported across Asia (Banyard et al., 2010; Parida et al., 2015) with an exception of lineage II vaccine virus involvement in a outbreak in wild ruminants in China (Zhou et al., 2017). The virus genome encodes for six structural (N, P, M, F, H \& L) and two nonstructural proteins (C \& V) (Bailey et al., 2005).

PPR situation in India is recently reviewed by our group and the outbreaks occur in all seasons (Muthuchelvan et al., 2015). With the availability of live attenuated PPR vaccine and MAb based competitive and sandwich ELISA, the Govt. of India has launched a national control program on PPR in 2010 which resulted in significant reduction of PPR outbreaks in some states. However, the protective herd immunity has yet to be established for the whole country (Muthuchelvan et al., 2014). The present vaccine being a live attenuated vaccine is expected to induce antibodies against all the viral proteins. Therefore, differentiating the infected from the vaccinated animals (DIVA) is difficult. Developing DIVA enabled vaccine and diagnostic assay will save money and labor during the eradication efforts.

The non-structural proteins $-\mathrm{C} \& \mathrm{~V}$ are encoded in the $\mathrm{P}$ ORF. The $\mathrm{C}$ protein is generated from an alternate start codon (Bailey et al., 2005; Muthuchelvan et al., 2006). It is a small basic nonphosphorylated protein with a molecular weight of 19-21 kDa. Two primary functions of $\mathrm{C}$ protein have been reported namely, prevention of host innate immunity and control of viral RNA synthesis (Garcin et al., 1999). It augments the maturation of infectious particle, has an antagonistic action against IFN and modulates RNA polymerase activity (Horvath, 2004). This protein can occur in both nucleus and cytoplasm of infected cells in Measles Virus and only in the cytoplasm of rinderpest virus (Patterson et al., 2000) and blocks the type I interferon in rinderpest virus (Boxer et al., 2009). Earlier we have reported the prokaryotic expression and confirmation of this protein (Bhadouriya et al., in press). In the present study, we have evaluated the reactivity of this protein in an indirect ELISA. The data generated in this study will be useful at the time of formulation of DIVA vaccine and diagnostics.

Serum samples having the serum neutralization (SNT) titer ranged from 1:8 to 1:256 from the vaccinated animals $(n=20)$ or convalescent sera $(n=20)$ available in the laboratory were used for checking the reactivity. The sera with SNT titre $<1: 2$ were used as negative control. The serum samples $(n=300)$ collected randomly from sheep/goats from different places of the country and were also included. To determine the time course of antibody production against this protein, we have vaccinated six animals with PPRV (Sungri/96) and collected the sera on 0, 7th, 14 th 28 th and $40^{\text {th }}$-day post vaccination.

A chequer-board titration was performed for optimization of antigen concentrations and antibodies dilutions (Bhadouriya et al., in press). The indirect ELISA was optimized inhouse, in brief; all the steps were carried out in $50 \mu \mathrm{L}$ reaction volumes and incubated at 37 ${ }^{\circ} \mathrm{C}$. After each incubation step, plates were washed three times with $100 \mu \mathrm{L} /$ well PBS containing $\quad 0.05 \% \quad$ Tween-20 (PBST). Recombinant C protein @ 100 ng/well, was suspended in carbonate-bicarbonate buffer ( $\mathrm{pH}$ 9.6). Wells were blocked with PBS containing 5\% skimmed milk powder and $2 \%$ chicken serum. The goat sera samples were diluted @ 1:10 in blocking buffer. 
Fig.1 Reactive pattern of recombinant PPRV C protein with vaccinated $(n=20)$, convalescent $(\mathrm{n}=20)$ and negative sera $(\mathrm{n}=20)$ in an indirect ELISA

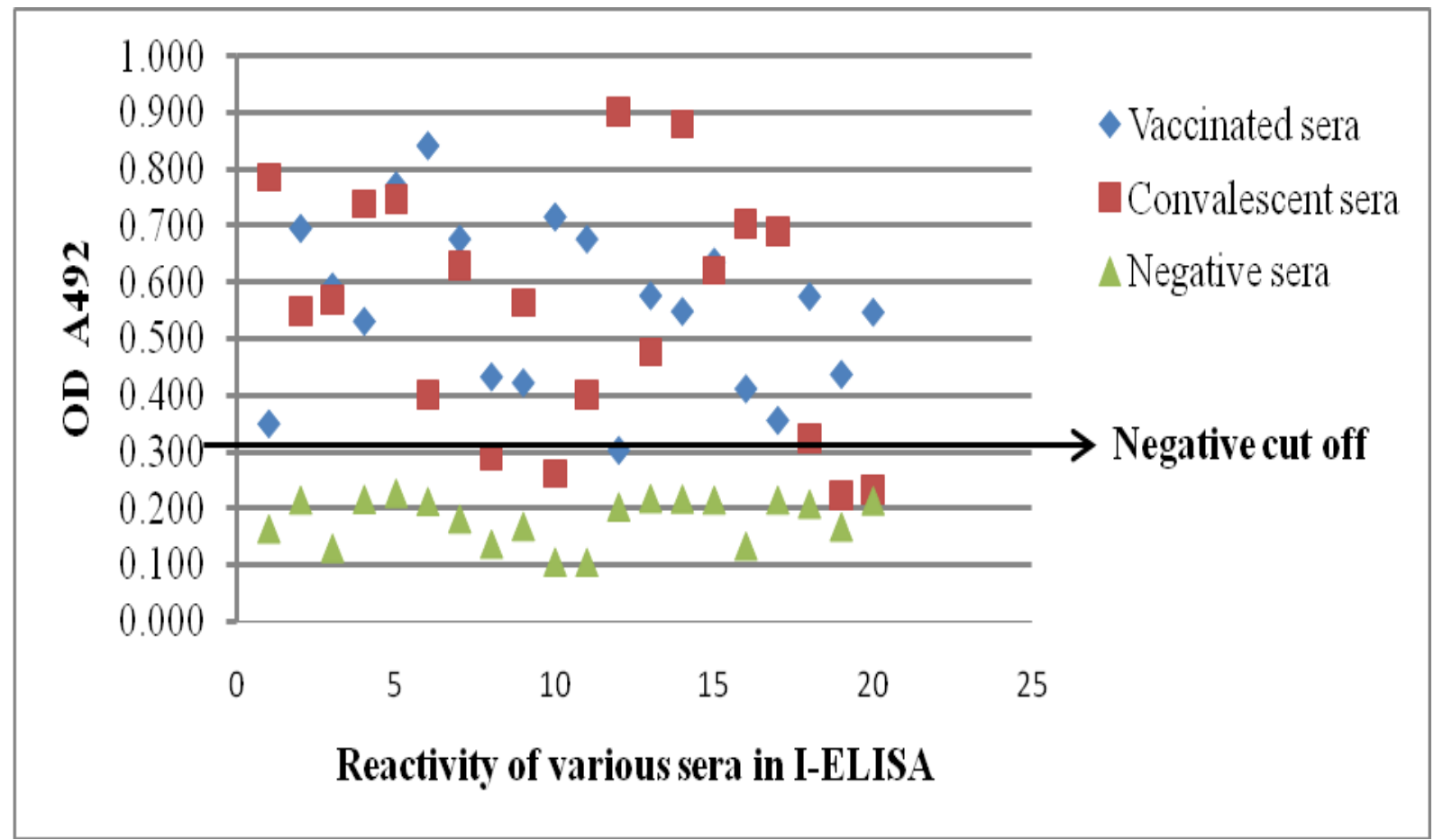

Fig.2 Time course analysis of the antibody production kinetics against $\mathrm{C}$ protein of PPRV in six vaccinated goats

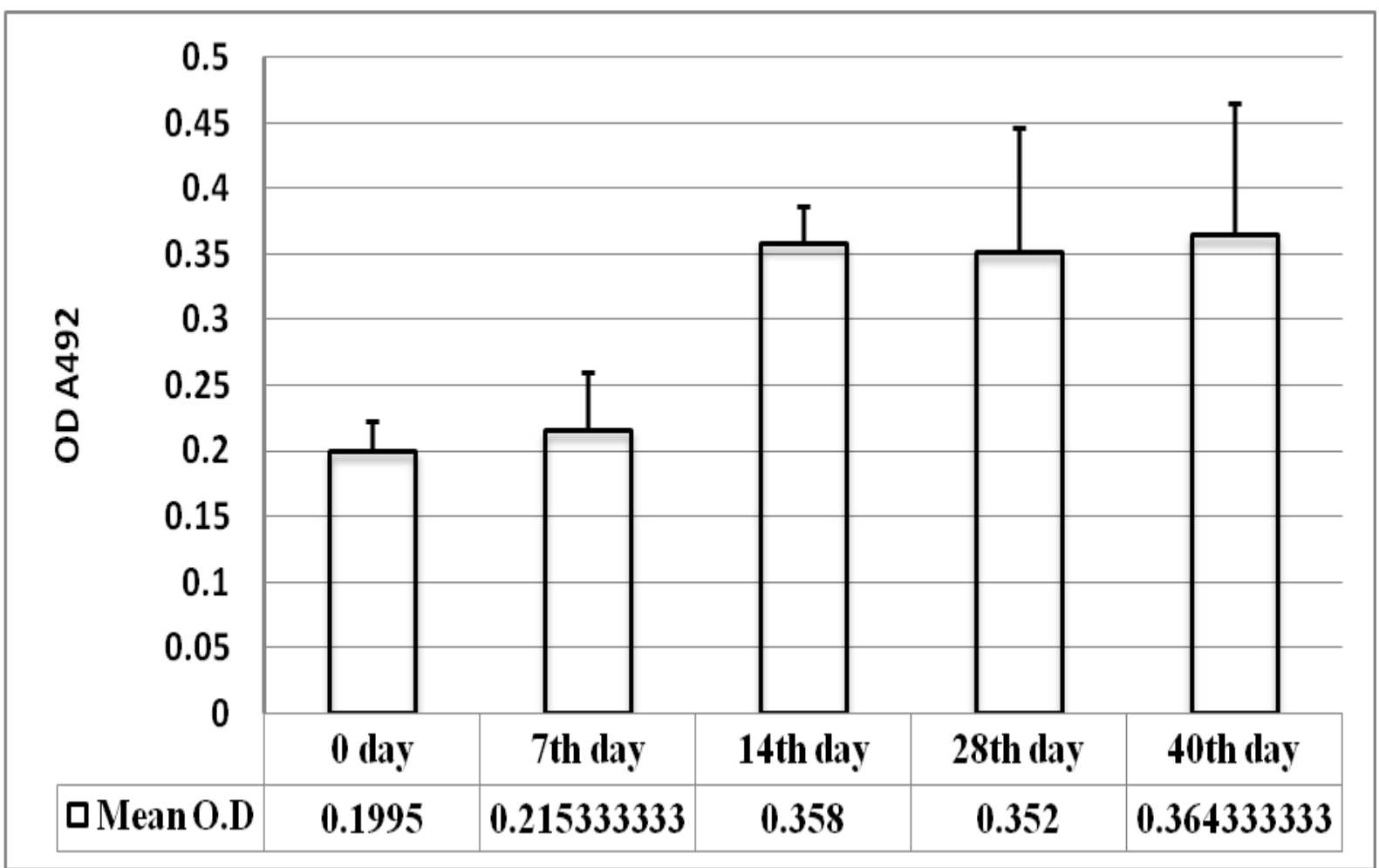


Fig.3 The ROC curve (A) and interactive dot diagram (B) obtained from a panel of 300 random sera from the field. The indirect ELISA developed using recombinant $\mathrm{C}$ protein of PPRV has a sensitivity of $76.3 \%$ and specificity of $65.28 \%$ when comparing the standard c-ELISA

A)

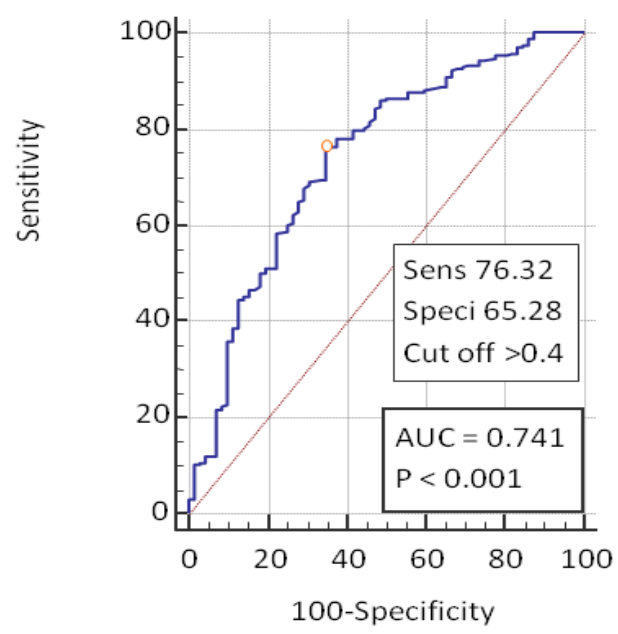

The anti-goat horseradish peroxidase conjugate (Sigma-Aldrich, USA) was used @ 1:5000 in blocking buffer. OPD substrate solution (OPD $1 \mathrm{mg} / \mathrm{mL}$ containing $4 \mu \mathrm{L} \mathrm{3 \%}$ $\mathrm{H}_{2} \mathrm{O}_{2}$ ) was added and incubated at $37{ }^{\circ} \mathrm{C}$ for $15 \mathrm{~min}$ followed by addition of $50 \mu \mathrm{L}$ of $1 \mathrm{M}$ $\mathrm{H}_{2} \mathrm{SO}_{4}$ to stop the reaction. The absorbance values were measured at $492 \mathrm{~nm}$ in an ELISA reader (Tecan, Switzerland).

The PPRV lineage four is expanding its territory in various regions of Africa, Europe, and Asia (Banyard et al., 2010; Parida et al., 2015). In the wake of the global control and eradication efforts, there is a need to develop modern vaccines and diagnostics that can differentiate the vaccinated from the infected animals (DIVA). At present, two groups have successfully rescued the PPR vaccine virus ( $\mathrm{Hu}$ et al., 2012; Muniraju et al., 2015). However, currently, there is no marker vaccine and diagnostic test available in the market. Developing marker vaccine by altering the non-structural proteins can be an attractive option. To adopt this strategy, we have earlier reported the successful
B)

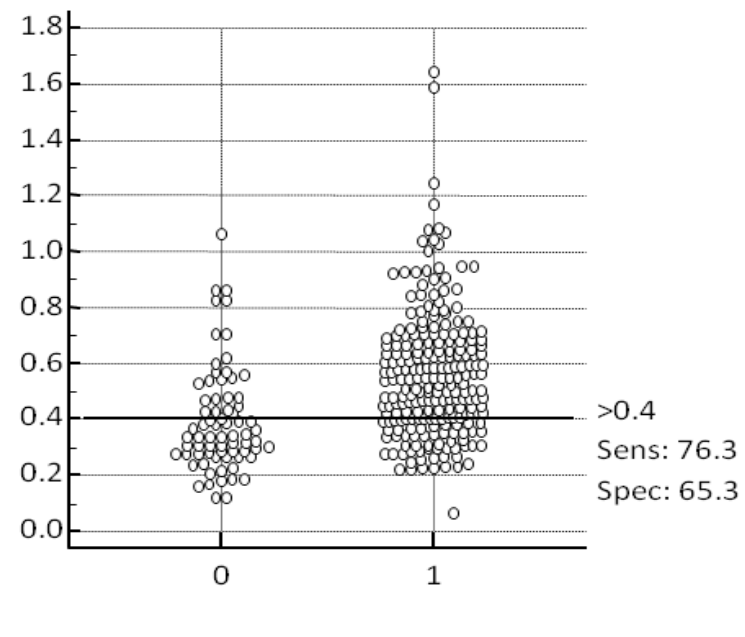

expression and development of a monospecific antibody against the nonstructural $\mathrm{C}$ protein of PPRV from vaccine virus (Bhadouriya et al., in press). In continuation of that, here we are reporting the reactivity profile of this protein against both the vaccinated and convalescent sera and we have also evaluated the antibody production kinetics of this protein in vaccinated goats.

The in-house optimized I-ELISA was used for determining the reactive pattern of convalescent and vaccinated sera. The optimum antigen (1 $\mu \mathrm{g}$ per well) and antibodies (the goat sera @ 1:4) concentration to use in I-ELISA were determined earlier (Bhadouriya et al., in press). The negative cut-off OD was determined to be 0.37 (mean $+2 \mathrm{SD})$ using known negative sera $(n=20)$ with an SNT titre of $<1: 2$. C protein being non-structural, the reactivity pattern of convalescent $(n=20)$ and vaccinated $(n=20)$ sera may differ as the vaccine virus could multiply only a few rounds in the animal whereas in natural infection the virulent virus evades the host defense and could multiply 
and spread to various tissues. However, we could find only minimal difference between the vaccinated and convalescent sera (Fig. 1). To get a conclusive picture, more sera from vaccinated and convalescent animals should be tested.

The time course analysis of antibody production kinetics reveals the seroconversion against this protein occurs from $14^{\text {th }}$-day post vaccination and the same level was maintained up to the study period of the 40th day (Fig. 2). This is not surprising as the live attenuated vaccine is expected to induce antibody against both structural as well as non-structural proteins. We have also evaluated the diagnostic potential of this protein using random field sera.

A total of three hundred field sera were tested both in c-ELISA and indirect ELISA and the result indicate that recombinant protein-based indirect ELISA has a sensitivity of $76.3 \%$ and specificity of $65.3 \%$ when compared with the standard c-ELISA (Fig. 3 A and B). The low level of sensitivity and specificity is expected as this protein is non-structural and shortlived in the host. More samples should be screened to get conclusive results.

In conclusion, here we have evaluated the reactivity pattern and antibody kinetics of the recombinant $\mathrm{C}$ protein of PPRV and the data generated in this study will be useful in developing marker vaccine and DIVA ELISA for PPR.

\section{Acknowledgements}

The authors would like to acknowledge funding from DBT-BBSRC BT/IN/IndoUK/FADH/50/GDR/2013 and ICAR-CRP sub-project 8 AS/2/7/2014-ASR-IV. BS acknowledges IVRI for financial support in terms of JRF to carry out the Master's degree Programme.

\section{Conflict of Interest}

The authors declare no conflict of interest.

\section{References}

Bailey, D., Banyard, A., Dash, P., Ozkul, A., Barrett, T., 2005. Full genome sequence of peste des petits ruminants virus, a member of the Morbillivirus genus. Virus Res. 110, 119-124.

Banyard, A.C., Parida, S., Batten, C., Oura, C., Kwiatek, O., Libeau, G., 2010. Global distribution of peste des petits ruminants virus and prospects for improved diagnosis and control. J. Gen. Virol. 91, 2885-2897.

Bhadouriya S, Choudhary D, Yadav A, Sekar SC, Dhanesh V V, Sankar M, Rajak KK, Singh R.P, Ramakrishnan MA and Muthuchelvan D 2018. Prokaryotic expression and confirmation of nonstructural protein $\mathrm{C}$ of peste-des-petitsruminants virus. Int.J.Curr.Microbiol. App.Sci (In Press).

Boxer, E.L., Nanda, S.K., Baron, M.D., 2009. The rinderpest virus non-structural $\mathrm{C}$ protein blocks the induction of type 1 interferon. Virology 385, 134-142.

Garcin, D., Latorre, P., Kolakofsky, D., 1999. Sendai virus $\mathrm{C}$ proteins counteract the interferon-mediated induction of an antiviral state. J. Virol. 73, 6559-6565.

Horvath, C.M., 2004. Silencing STATs: lessons from paramyxovirus interferon evasion. Cytokine Growth Factor Rev. 15, 117-127.

Hu, Q., Chen, W., Huang, K., Baron, M.D., $\mathrm{Bu}, \mathrm{Z} ., 2$ 2012. Rescue of recombinant peste des petits ruminants virus: creation of a. Vet. Res. 43, 48.

Kwiatek, O., Minet, C., Grillet, C., Hurard, C., Carlsson, E., Karimov, B., Albina, E., Diallo, A., Libeau, G., 2007. Peste des petits ruminants (PPR) outbreak in Tajikistan. J. Comp. Pathol. 136, 111- 
119.

Muniraju, M., Mahapatra, M., Buczkowski, H., Batten, C., Banyard, A.C., Parida, S., 2015. Rescue of a vaccine strain of peste des petits ruminants virus: In vivo evaluation and comparison with standard vaccine. Vaccine 33, 465-471.

Muthuchelvan, D., De, A., Debnath, B., Choudhary, D., Venkatesan, G., Rajak, K.K., Sudhakar, S.B., Himadri, D., Pandey, A.B., Parida, S., 2014. Molecular characterization of peste-despetits ruminants virus (PPRV) isolated from an outbreak in the IndoBangladesh border of Tripura state of North-East India. Vet. Microbiol. 174, 591-595.

Muthuchelvan, D., Rajak, K.K., Ramakrishnan, M.A., Choudhary, D., Bhadouriya, S., Saravanan, P., Pandey, A.B., Singh, R.K., 2015. Peste-despetits-ruminants: An Indian perspective. Adv Anim Vet Sci 3, 422-429.

Muthuchelvan, D., Sanyal, A., Sarkar, J., Sreenivasa, B.P., Bandyopadhyay, S.K., 2006. Comparative nucleotide sequence analysis of the phosphoprotein gene of peste des petits ruminants vaccine virus of Indian origin. Res. Vet. Sci. 81, 158-
164.

Parida, S., Muniraju, M., Mahapatra, M., Muthuchelvan, D., Buczkowski, H. Banyard, A.C., 2015. Peste des petits ruminants. Vet. Microbiol. 181, 90-106. Patterson, J.B., Thomas, D., Lewicki, H., Billeter, M.A., Oldstone, M.B., 2000. V and $\mathrm{C}$ proteins of measles virus function as virulence factors in vivo. Virology 267, 80-89.

Sen, A., Saravanan, P., Balamurugan, V., Rajak, K.K., Sudhakar, S.B., Bhanuprakash, V., Parida, S., Singh, R.K., 2010. Vaccines against peste des petits ruminants virus. Expert Rev. Vaccines 9, 785-796.

Shaila, M.S., Shamaki, D., Forsyth, M.A., Diallo, A., Goatley, L., Kitching, R.P., Barrett, T., 1996. Geographic distribution and epidemiology of peste des petits ruminants virus. Virus Res. 43, 149-153.

Zhou, X.Y., Wang, Y., Zhu, J., Miao, Q.-H., Zhu, L.Q., Zhan, S.H., Wang, G.J., Liu, G.Q., 2017. First report of peste des petits ruminants virus lineage II in Hydropotes inermis, China. Transbound. Emerg. Dis. https://doi.org/10.1111/tbed.12683

\section{How to cite this article:}

Bhadouriya Sakshi, Dheeraj Choudhary, Ajay Yadav, S. Chandra Sekar, V.V. Dhanesh, M. Sankar, Kaushal K. Rajak, R.P. Singh, M.A. Ramakrishnan and Dhanavelu Muthuchelvan. 2018. Evaluation of Reactivity Profile of Non-Structural Protein C of Peste-Des-PetitsRuminnats Virus. Int.J.Curr.Microbiol.App.Sci. 7(02): 3105-3110. doi: https://doi.org/10.20546/ijcmas.2018.702.373 